\title{
New Digital Media and Flow: A Study of Experience*
}

\author{
Daniel T. Gruner \\ Department of Psychology, Claremont Graduate University, USA \\ E-mail address: daniel.gruner@cgu.edu
}

\section{ARTICLE INFO}

\section{Keywords:}

New digital media

Flow

Experience sampling

\section{Article history:}

Received: 14 March 2016

Received in revised form: 30 July 2016

Accepted: 8 October 2016

ISSN: 2354-0036

DOI: $10.1515 /$ ctra-2016-0021

\section{A B S T R A C T}

The burgeoning use of new digital media (NDM) platforms for social networking such as Facebook, Twitter, and Instagram has consistently been associated with out-group prejudice, less prosocial behaviour, less fulfilling friendships, and lower levels of moral reflection, integrity, and subjective wellbeing. But the context of NDM use is often neglected when examining its psychological effects. Moreover, such studies are limited to retrospective accounts and can benefit from examining episodic experiences of flow, boredom, apathy, and anxiety. Drawing on data collected using the Experience Sampling Method (ESM), this study assessed the psychological impact of social networking on low and high media users. Participants $(N=65)$ were signaled six times per day for seven days and asked to respond to brief surveys about subjective momentary experiences. Findings indicated that high media users, on average, reported less positive moods, and also reported being significantly less creative and less energetic each day. Further, high media users reported deriving less meaning from daily activities, and were marginally less satisfied with the overall quality of their week than their low media user counterparts. When comparing all media users across flow quadrants, creativity, meaning, engagement, and energy levels were highest in flow, and substantially decreased across the remaining quadrants. Notably, self reported mood was slightly higher during instances of boredom than flow. However, a more nuanced comparison of these outcomes revealed that high media users reported being marginally more creative and engaged during boredom, thereby identifying differences in how the two groups approached social media.

In the past decade, there has been a substantial shift towards the use of online social networking platforms for interpersonal communication (Hofferth, 2010; Immordino-Yang, Christodoulou, \& Singh, 2012; Twenge, 2013). Replacing face-to-face communication with new digital media (NDM) has been theorized to displace critical developmental

\footnotetext{
* The author would like to thank Mihaly Csikszentmihalyi, Jeanne Nakamura, Atsushi Kukita, and Jeffery Fajans for their helpful contributions.
} 
mechanisms such as friendship formation, study time, play, physical activation, sleep, and offline social interaction (Immordino-Yang et al., 2012; Neuman, 1991). Moreover, high media use might have a detrimental impact on emotion regulation, creativity, moral evaluation, and subjective well-being (Hofferth, 2010; Hur \& Gupta, 2013; Kross et al., 2013), and can lead to loneliness (Hofferth, 2010; Immordino-Yang et al., 2012). However, given that digitally mediated social networks are becoming an increasingly pragmatic platform for interaction among people of all ages, they can also be seen as a medium for amplifying youths' civic voices, fostering connections, and "staying in touch" with others (James, Gruner, Lee, \& Mullen, 2016).

Although heavy media use has been linked to aggression and antisocial behaviour, moderate use has been associated with academic achievement for certain people under certain conditions (Subrahmanyam, Greenfield, Kraut, \& Gross, 2001). Importantly, this difference might not only manifest due to time spent using media, but the quality and context of use (e.g., video games, movies, social interaction, or learning platforms). Furthermore, young people are using NDM in increasingly creative ways to express their political opinions online, which also empowers traditionally underrepresented voices (James et al., 2016). Thus, it is important to better understand how varied interactions with social media account for the different ways in which individuals experience NDM on a phenomenological level.

The present study addresses these issues by using the Experience Sampling Method (ESM; Larson \& Csikszentmihalyi, 1983) to explore relationships between low versus high users of digitally mediated social networks and various experiential outcomes including mood, creativity, meaning, engagement, and energy levels. In addition, low and high media users are compared across four psychological states - flow, boredom, apathy, and anxiety - to explore how NDM impact daily human experience.

\section{NEW DIGITAL MEDIA AND THE QUALITY OF EXPERIENCE}

Two theories are helpful for discussing the potentials of NDM in altering human experience (Gerbner, Gross, Morgan, Signorielli, \& Shanahan, 2002). On the one hand, Displacement Theory (Neuman, 1991) suggests that frequent use of NDM replaces social processes that contribute to normative development. For example, computers might effectuate social isolation by reducing the amount of time individuals spend interacting face -to-face or playing outdoors, which are critical components of psychosocial learning and physical activation (Piaget, 1971; Piaget \& Inhelder, 1963; Vygotsky, 1978). Similarly, the attentional resources individuals invest in activities are limited; if one devotes too much time to NDM, they will have less to expend in other social activities, unless they engage in multitasking, which is often linked with anxiety and occurs when using multiple plat- 
forms (Immordino-Yang et al., 2012). For example, individuals can be checking Facebook on their computers while watching television and instant messaging all at the same time, which in turn consumes most cognitive resources (Immordino-Yang et al., 2012). Importantly, displacement occurs in different ways; text messaging can replace talking on the phone, while using Facebook can replace offline engagement with others (Neuman, 1991). Similarly, NDM can replace more productive activities with (potentially) less productive ones, becoming a distraction rather than useful networking tool (Hofferth, 2010). Understandably, spending time on sites such as Facebook or Twitter can detract from pressing work or study demands, in turn contributing to lower achievement and neglecting desired goals.

On the other hand, Cultivation Theory (Gerbner et al., 2002) suggests that increased use and exposure to digital media alters individuals' perspectives of others and their immediate social structures. That is, it can potentially enforce stereotypes or restructure how individuals make moral evaluations, ethical decisions, and solve problems. Indeed, NDM can also construct positive norm-based change if used ethically and responsibly. However, newly enforced self-other perceptions, especially when projected as negative, can have adverse effects on self-esteem, self-confidence, self-efficacy, and contribute to social isolation (Gerbner et al., 2002; Hofferth, 2010). This paradox thus provides a useful point of departure to investigate how NDM is associated with experiences of flow, boredom, apathy, and anxiety, which are typically linked both positively and negatively with creativity, engagement, meaning, and happiness (Csikszentmihalyi, 1988, 1990, 1997; Nakamura \& Csikszentmihalyi, 2009).

New digital media have also been attributed to shifts in creative thinking and productivity. For example, Weigel, Straughn, Gardner, and James (2008) found that some educators observed diminished creative processes among adolescent students across a variety of thought domains (e.g., art, music, games, and academic work), while others suggested that exposure to multiple digital media platforms could benefit creative thinking because they provide students with novel ideas from which to build. However, some educators further noted that increased use of NDM consumes time that might otherwise be invested in creative reflection, similar to the process of displacement. Moreover, media use can heighten expectations from students, which in turn could decrease enjoyment of the creative process due to its added competitive nature (Weigel et al., 2008). While studies on NDM and human experience are indeed increasing, many yield inconsistencies, and more research is still needed to parse the benefits and drawbacks of media-based interaction given the shift towards a more contemporary, tech-literate society (Immordino-Yang et al., 2012; Twenge, 2013; Weigel et al., 2008). Due to such mixed 
findings, it is important to further investigate how media use operates in the context of optimal experiences such as flow.

\section{FLOW - THE OPTIMAL HUMAN EXPERIENCE}

Flow is an optimal human experience that occurs when one is completely involved in an activity that provides a matched balance of high challenges and high skills (Csikszentmihalyi, 1988, 1990, 1997; Nakamura \& Csikszentmihalyi, 2009; Schuler \& Nakamura, 2013). The experience is often predicated on having clear goals (i.e., knowing what to do) and immediate feedback about how well the task is being accomplished in the moment. The flow experience has been described as a feeling of intense concentration resulting in a "merging of action and awareness" such that the investment of attentional resources is fully occupied by the activity itself, thereby leaving no residual bits of information to allocate elsewhere. In addition, people describe a "distorted sense of time" and loss of self-awareness, or transcendence, such that there is a temporal dissolution of the ego where self-referential hyperegoic processes attributed to prefrontal cortex activation are downregulated (Csikszentmihalyi, 1988; Ulrich, Keller, Hoenig, Waller, \& Grön, 2014). Numerous studies have revealed the implications of flow for personal growth and happiness, and thus, readers are directed elsewhere for a more in-depth discussion of the topic (e.g., Csikszentmihalyi \& Csikszentmihalyi, 1988).

Csikszentmihalyi's (1997) flow model defines eight distinct channels categorized by optimal and suboptimal experiences according to matched levels of perceived challenges and skills. This study collapses those eight channels into the four quadrants described below (see Figure 1). Because phenomenology is central to flow theory, it is the perceived experiences of individuals that matter most (Csikszentmihalyi, 2000). That is, perceived high-challenge/high-skill activities engender flow, while perceived low-skill/lowchallenge activities elicit apathy. Further, high-skill/low-challenge activities elicit boredom, while low-skill/high-challenge activities elicit anxiety. Scholars have previously used these quadrants to compare the quality of experiences across person-centered and situationcentered contexts (Hektner, Schmidt, \& Csikszentmihalyi, 2007; LeFevre, 1988; Nakamura, 1988). Here, the flow quadrants are used in a person-centered approach to compare low and high social media users across various experiential outcomes. Although studies have been conducted on flow experiences and digitally-mediated human behaviour (e.g., Gupta \& Kabadayi, 2013; Hsu, Chang, \& Chen, 2012; Thatcher, Wretschko, \& Fridjhon, 2008), research that explores the relationship between flow and social interaction through NDM is limited (Voiskounsky, 2012). 
high

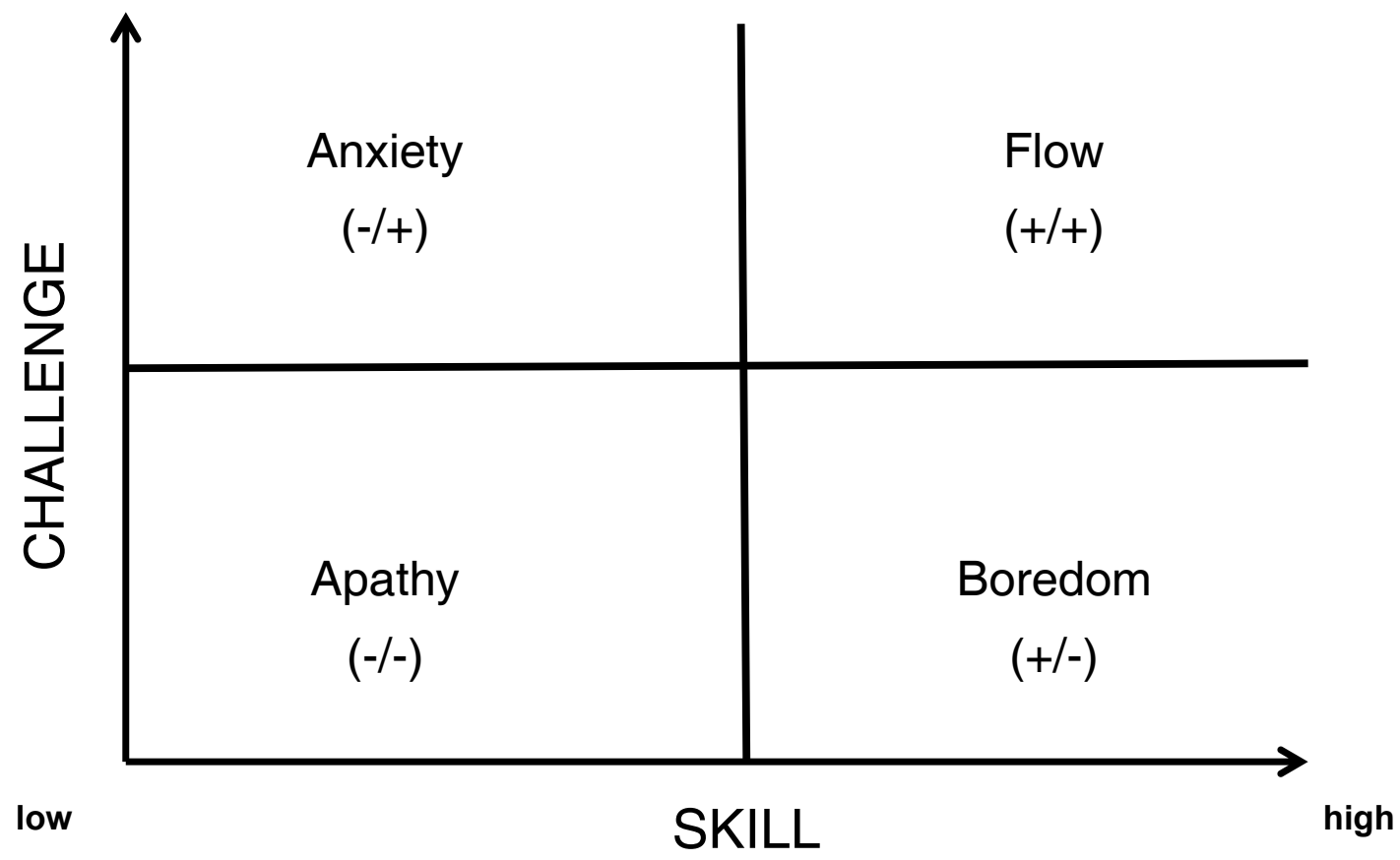

Figure 1. Flow Quadrants Conceptual model of collapsed flow quadrants adapted from Csikszentmihalyi (1997)

Note: Plus (+) and minus (-) symbols represent positive and negative z-scores associated with skill and challenge levels respectively.

\section{THE PRESENT STUDY}

This study aims to contribute to our understanding of the psychological impact of NDM. Given that digital media is becoming a ubiquitous source of social interaction (Hofferth, 2010; Twenge, 2013; Weigel et al., 2008), and that NDM have been associated with both positive and negative psychosocial outcomes (Immordino-Yang et al., 2012; Kross et al., 2013; Rocheleau, 1995), it is important to further explore how online activities impact momentary experiences. In accordance with previous literature (Kross et al., 2013), the present study posits that high media users will report lower mood levels than low media users (hypothesis 1). Furthermore, the present study posits that high media users will report lower levels of creativity (hypothesis 2). In addition, it is postulated that high media users will report being less engaged and derive less meaning from daily activities (hypothesis 3 ). It is also proposed that high media users will report lower energy levels during the study period than their low media user counterparts (hypothesis 4). An exploratory component of this study assesses how low and high media users experience mood, creativity, engagement, meaning, and energy levels across flow quadrants, and also examines differences in their daily and weekly satisfaction levels. Although this study component is purely exploratory, it is expected that mood, creativity, meaning, engagement, and energy will be highest during flow, and lowest during apathy (hypothesis 5). 


\section{METHOD}

\section{Participants and Design}

The present study utilized the experience sampling method (ESM) via a new platform called the Personal Analytics Companion (PACO). As PACO runs exclusively on handheld Android and iPhone devices, participation was limited to individuals who currently use either Android or iPhone mobile phones. Participants were recruited via online social networks and word of mouth, and were enrolled in their seven-day participation period on a rolling basis (i.e., participants did not all start and end on the same dates, but instead started their seven-day period on a date convenient to them). Based on past experience with similar studies, this rolling participation approach helps increase participation rates and decrease attrition. Participation was entirely voluntary, and a $\$ 20$ incentive for full participation in all aspects of the study was provided to participants at study completion as compensation. Also upon study completion, an informational summary of the results was offered to any interested participants.

Of the initial set of individuals who indicated that they were interested in participating $(N=75)$, about $96 \%$ participated in the ESM portion of the study and provided 10 or more complete responses $(N=72)$; about $91 \%$ participated in all phases of the study $(N=68)$. The participants in the full study (38 women, 30 men, $M_{\text {age }}=31.12$ years, age range: 18-74) consisted primarily of working professionals and full-time students. Regarding the highest level of education completed, $47 \%$ of participants held a college degree (i.e., BA, BS, etc.), 28\% held a master's degree (i.e., MBA, MA, MSW, etc.), 4\% a professional degree (i.e., MD, PhD, JD, etc.), 15\% had completed "some college," and $6 \%$ had completed "high school or less." Participants were allowed to select "all that apply" in regards to which race they considered themselves. Of the individuals who indicated their race/ethnicity, 44 identified as Caucasian, 13 identified as Asian/Pacific Islander, 5 identified as Hispanic, 5 identified as Black/African American, 3 identified as Native American/Alaska Native, and 5 indicated that they identified as Other/Multi-racial.

\section{Procedure}

The study design called for individuals to be signaled via PACO six times a day for seven days, at random intervals, between the hours of $8 \mathrm{am}$ and $10 \mathrm{pm}$. There were times when participants were unable to respond to signals, were unaware that they were being signaled, forgot their devices, or PACO had malfunctioned. For the 72 participants, $n=2,405$ complete responses were generated (about a $54 \%$ response rate).

In addition, individuals completed a single-item End of Day (EOD) survey to capture additional information about their day. Participants were instructed to choose a time to complete the EOD survey that would be close to when their day was truly over to max- 
imize accurate reporting. Participants had the opportunity to complete the EOD survey each day that they participated in the study. There were also times when participants either forgot to complete the EOD survey or otherwise missed the signal, which led to $n=526$ responses for the EOD survey, or about an $81 \%$ response rate.

Each participant was trained on how to operate PACO as part of the onboarding process. These training sessions were conducted either through an in-person consultation or over the telephone by a member of the research team. Finally, following the completion of the seven days of participation, individuals were given a link to complete a survey on Qualtrics that would provide additional information about demographic variables and other personality measures. A total of 68 individuals completed the final survey. Because some participants consistently provided incomplete data during the study period, they were removed from the final analyses, resulting in a final sample of $N=65$ participants.

\section{Measures}

Media use. Social media use was measured by asking participants to rate one question at each signal ("since you were last beeped, to what extent have you used any social networking sites such as Facebook, Twitter, or Instagram?") ranging from 1 (not at all) to 7 (a lot). Signal-level responses were used in mixed model designs. In addition, signal-level responses were aggregated across participants so that a grand mean for each individual was generated. A median split was then used to dichotomize participants into low media users $(n=33$, range $=1.00-2.33)$ and high media users $(n=32$, range $=$ 2.34 -4.97). The median split was used to identify differences between groups.

Flow. Participants were asked to rate two items at each signal ("how challenged did you feel?" and "how skilled did you feel?") ranging from 1 (not at all) to 7 (extremely). Signal-level responses were standardized around each participant's average to capture intraindividual variability. Using z-scores provides an account of momentary experience relative to individual baseline levels rather than grand means. In accordance with previous studies (e.g., LeFevre, 1988; Nakamura, 1988), four quadrants were generated (flow, boredom, apathy, anxiety) by z-scores. That is, when challenges and skills were both higher than baseline (z-scores greater than 0), responses fell within the flow quadrant. When skills were high but challenges low, responses fell within the boredom quadrant. When skills and challenges were both low (z-scores less than 0 ), responses fell within the apathy quadrant. When challenges were high and skills were low, responses fell within the anxiety quadrant (see Figure 1). Thus, the eight channels described in Csikszentmihalyi's revised flow model were collapsed into these four quadrants. 
Quality of experience. A series of questions ("how engaged in the activity did you feel," "how creative were you being," "how meaningful was the activity you were doing," and "how energetic did you feel") were rated on 7-point Likert scales ranging from 1 (not at all) to 7 (extremely) at each signal to measure engagement, creativity, meaning, and energy levels. Signal-level responses were used for mixed model designs and between group comparisons. Standardized z-scores of signal-level responses were also used to compare intraindividual variability across flow quadrants.

Mood. Mood was assessed by asking respondents one question ("what was your mood?") rated on a 7-point Likert scale from 1 (very negative) to 7 (very positive). Again, signal-level responses were used for mixed models and between group comparisons. In addition, z-scores were used to examine intraindividual variability across flow quadrants.

Satisfaction with day and week. At the end of each day, participants were asked one question ("what was the quality of your day?") ranging from 1 (awful) to 7 (great). Daily satisfaction was aggregated at the person-level from signal-level responses to generate a grand mean for each subject. Subjects were asked a similar question at the end of the study period ("how unsatisfied or satisfied were you with your week?"). Here, person-level scores were used for data analytics because subjects completed only one EOW survey during the study.

\section{RESULTS}

Pearson bivariate correlations of signal-level responses were first examined to assess relationships among variables. Means, standard deviations, and intercorrelations are displayed in Table 1. Social media use was not significantly correlated with mood $(r=-.02$, $p=.29)$ and further demonstrated negligible associations with all experiential outcomes. Even when significant associations with social media use emerged, the strongest was between media use and self-reported meaning $(r=-.07, p<.001)$. However, because the sample size was so large ( $n=2,292$ signal-level responses), this should be considered a small effect. Interestingly, all correlations with social media showed trending negative effects. In contrast, the strongest positive correlations were between engagement and meaning $(r=.68, p<.001)$, followed by creativity and skill $(r=.58, p<.001)$, and mood and energy $(r=.58, p<.001)$. Creativity was also highly correlated with challenge $(r=.55, p<.001)$ and energy levels $(r=.50, p<.001)$. 


\section{Table 1}

Means, standard deviations, and intercorrelations of key variables

\begin{tabular}{|c|c|c|c|c|c|c|c|c|c|c|}
\hline & $M$ & $S D$ & 1 & 2 & 3 & 4 & 5 & 6 & 7 & 8 \\
\hline 1. Media Use & 2.35 & 1.49 & -- & & & & & & & \\
\hline 2. Skill & 3.25 & 1.78 & .01 & -- & & & & & & \\
\hline 3. Challenge & 2.95 & 1.74 & $-.06^{* *}$ & $.49^{* \star *}$ & -- & & & & & \\
\hline 4. Meaning & 4.39 & 1.65 & $-.07^{\star \star \star}$ & $.38^{* * *}$ & $.34^{\star \star \star}$ & -- & & & & \\
\hline 5. Engagement & 4.75 & 1.53 & $-.05^{*}$ & $.38^{* * *}$ & $.31^{* * *}$ & $.68^{\star * \star}$ & -- & & & \\
\hline 6. Energy & 4.06 & 1.46 & $-.05^{*}$ & $.39^{* * *}$ & $.27^{\star \star \star}$ & $.50^{* * *}$ & $.55^{\star \star *}$ & -- & & \\
\hline 7. Creativity & 2.89 & 1.68 & $-.05^{*}$ & $.58^{* * *}$ & $.55^{\star \star \star}$ & $.38^{* \star *}$ & $.37^{* \star *}$ & $.50^{* * *}$ & -- & \\
\hline 8. Mood & 4.82 & 1.20 & -.02 & $.23^{* * *}$ & $.06^{*}$ & $.39^{* \star *}$ & $.44^{* \star *}$ & $.58^{* * \star}$ & $.32^{* * *}$ & -- \\
\hline
\end{tabular}

Note. ${ }^{\star} p<.05 ;{ }^{* \star} p<.01 ;{ }^{* \star *} p<.001$, two-tailed. Bivariate correlations conducted on 2,292 signal-level responses.

Given that signal-level responses were nested by subjects, data were then unpacked using a multilevel model (MLM) design. Intraclass correlation coefficients (ICC) were determined by the following equation:

$$
\rho=\sigma^{2}{ }_{b} /\left(\sigma_{b}^{2}+\sigma^{2}{ }_{w}\right)
$$

where rho $(\rho)$ equals ICC when $\sigma^{2}{ }_{b}$ represents between group variance and $\sigma^{2}{ }_{w}$ represents within group variance. The ICC indicates how much variability is attributed to individual differences. All ICC values for nested models suggested that MLM was appropriate (ICC range $=.16-.34)$. To further interpret associations, a series of mixed models with fixed and random effects were introduced by the following 2-level equation:

$$
\operatorname{Mood}_{i j}=v_{00}+v_{10} \times \operatorname{Var}_{i j}+u_{0 j}+e_{i j}
$$

Here, mood scores for subject $j$ at signal $i$ are predicted by the independent variables $\left(\operatorname{Var}_{i j}\right)$ social media use, creativity, engagement, energy, and meaning. Components $u_{0 j}$ and $e_{i j}$ represent error terms within and between subjects respectively, $v_{00}$ represents an individual's grand mean, and $\gamma_{10}$ is the effect. Thus, the above equation accounts for individual variability by participant and includes an additional predictor variable from signallevel responses (Hayes, 2006).

Results showed that social media use was not a significant predictor of mood, $\gamma_{10}=.008, S E=.021, t(72)=.394, p=.70$, which corroborates the simple correlation above. However, creativity was a significant predictor, $\gamma_{10}=.218, S E=.016, t(69)=13.116$, 
$p<.001$, as was engagement, $v_{10}=.319, S E=.016, t(235)=20.429, p<.001$, energy, $\gamma_{10}=.433, S E=.016, t(264)=27.605, p<.001$, and meaning, $\gamma_{10}=.253, S E=.016$, $t(192)=15.544, p<.001$.

To predict mood of subject $j$ at signal $i$ from each independent variable controlling for gender, a secondary mixed model was tested as follows:

$$
\operatorname{Mood}_{i j}=v_{00}+v_{10} \times \operatorname{Var}_{i j}+v_{20} \times \text { Gender }+u_{0 j}+e_{i j}
$$

Results showed that social media use was again not a significant predictor of mood when controlling for gender $\gamma_{20}=.008, S E=.022, t(65)=.349, p=.728$. However, all other variables were still significant predictors when gender was controlled, including creativity, $\gamma_{20}=.214$, $S E=.017, t(63)=12.454, p<.001$, engagement, $v_{20}=.322, S E=.016, t(220)=20.071$, $p<.001$, energy, $\gamma_{20}=.436, S E=.016, t(212)=26.361, p<.001$, and meaning, $\gamma_{20}=.251$, $S E=.017, t(171)=14.771, p<.001$.

Low and high media users. Independent samples t-tests using signal-level data were then employed to assess differences in means between low and high media users on each of the five experiential outcomes (i.e., mood, creativity, engagement, meaning, and energy); the overall satisfaction with their day, and overall satisfaction with their week were also examined. Here, findings indicated differences between groups such that high media users reported less positive moods throughout the week $(t=3.82, p<.001)$, which reveals a significant difference that was not captured by the linear models above. Furthermore, the high media users reported being less creative $(t=3.19, p=.001)$, and significantly less energetic $(t=3.48, p=.001)$. In addition, the high media users derived less meaning ( $t=2.31, p=.021)$ from activities than their low media user counterparts. However, low and high media users did not differ significantly on their reported levels of engagement $(t=1.61, p=.107)$. Finally, high media users did not differ significantly in their satisfaction with each day $(t=0.45, p=.66)$, but were marginally less satisfied with their week overall ( $t=1.34, p=.08)$. Table 2 displays the means, standard deviations, and degrees of freedom of variables between the two groups. Following the analysis of between group differences, a more nuanced approach was applied to identify differences in how media users experienced each of the flow quadrants. 
Table 2

Quality of Experience of Low $(n=33)$ and High $(n=32)$ Media Users

\begin{tabular}{lccccccc}
\hline & $\begin{array}{c}\text { Mean Score } \\
\text { Low Users }\end{array}$ & SD & $\begin{array}{c}\text { Mean Score } \\
\text { High Users }\end{array}$ & SD & $\boldsymbol{t}$ & $\boldsymbol{d f}$ & $\boldsymbol{p}$ \\
\hline Meaning & 4.46 & 1.66 & 4.30 & 1.64 & 2.309 & 2290 & .021 \\
Engagement & 4.80 & 1.49 & 4.70 & 1.56 & 1.614 & 2290 & .107 \\
Energy & 4.16 & 1.52 & 3.95 & 1.40 & 3.483 & 2290 & .001 \\
Creativity & 3.00 & 1.73 & 2.77 & 1.62 & 3.185 & 2290 & .001 \\
Mood & 4.92 & 1.23 & 4.72 & 1.16 & 3.823 & 2290 & $<.001$ \\
Day Overall & 5.26 & 0.67 & 5.19 & 0.61 & 0.445 & 57 & .66 \\
Week Overall & 5.35 & 1.11 & 4.79 & 1.34 & 1.767 & 58 & .08 \\
\hline
\end{tabular}

Note. Significance values are two tailed. Sample contains 65 subjects and 2,292 responses. Signal-level responses used for meaning, engagement, energy, creativity, and mood. Signal-level responses aggregated at the individual level for satisfaction with day (Day Overall). Person-level raw scores used for satisfaction with week (Week Overall). Missing cases were deleted pairwise.

Flow quadrants. Two sets of analyses were employed to assess the quality of experience across four psychological states defined by flow quadrants (i.e., flow, boredom, apathy, anxiety). First, standardized z-scores were computed for self-reported mood, creativity, engagement, meaning, and energy levels across all respondents, ignoring the lowhigh median split of media use. Next, z-scores were computed for high media users and low media users separately to compare their quality of experience across flow quadrants.

Figure 2 displays all respondents' average levels (i.e., intraindividual variability) of outcome variables across quadrants. Findings indicated that each of these outcomes, with the exception of mood, is highest (above baseline) when both challenges and skills are matched and high (i.e., flow), and decrease across the remaining quadrants clockwise. Taken together, respondents reported their lowest levels of creativity, engagement, meaning, and energy when in the low skills / low challenges quadrant (i.e., apathy). However, mood was the lowest for all participants during moments of anxiety. In parallel, all respondents reported being most creative, engaged, energetic, and found activities to be most meaningful during flow. Unexpectedly, mood was slightly more positive during boredom (when perceived skills are higher than the challenges offered) than flow. The next analysis then compared these five experiences across flow quadrants with regards to low and high media users. 


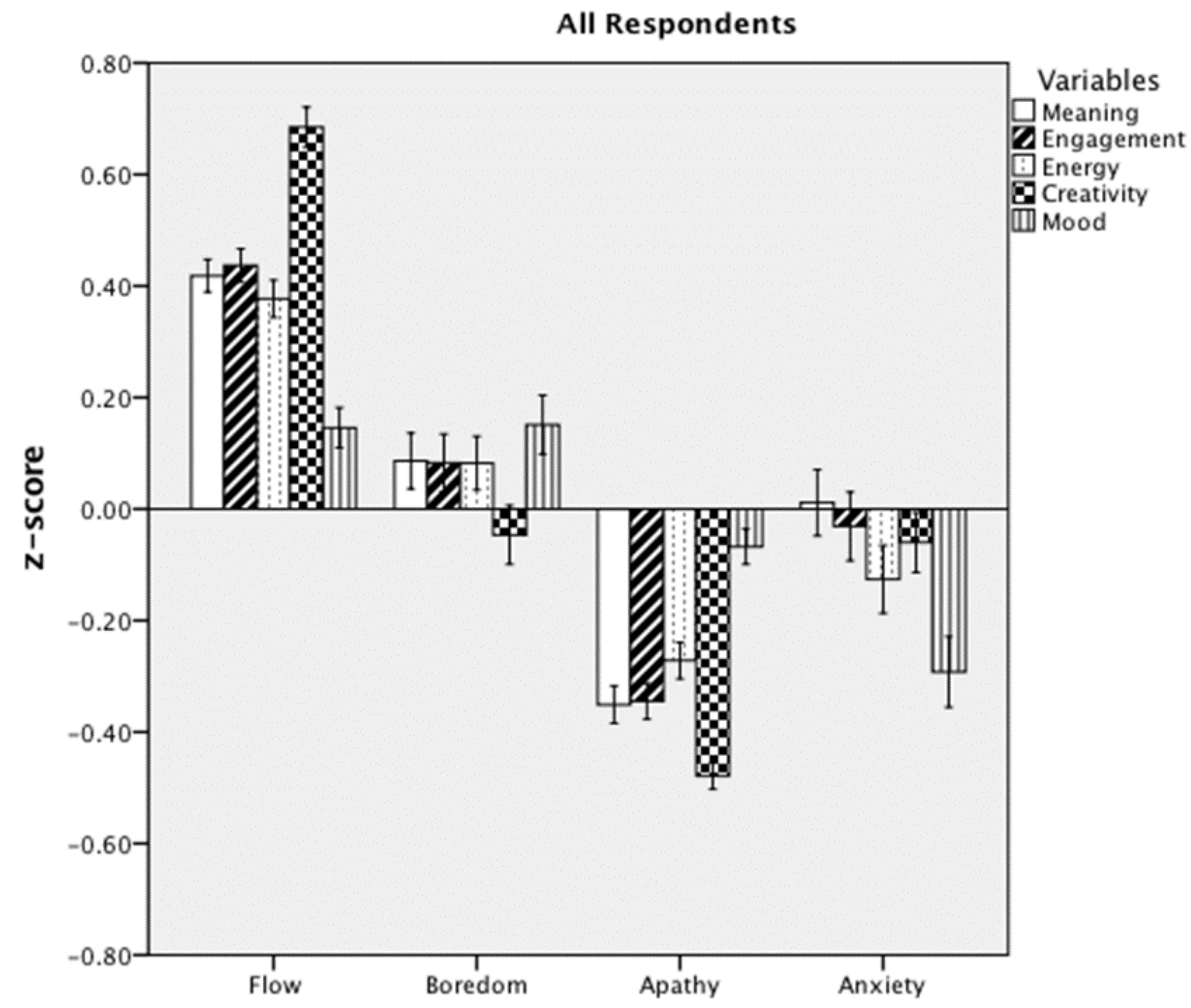

Figure 2. Quality of Experience Across Quadrants: All Respondents Average quality of experience in flow quadrants across all participants $(N=65$ subjects and 2,292 responses). Error bars indicate $+/-1$ standard error

For both low and high media users, creativity, engagement, meaning, and energy levels were still highest in the flow quadrant (see Figure 3 and Figure 4). However, a trending difference of mood emerged such that high media users reported higher mood levels during boredom than flow, while the low media users reported higher mood during flow than boredom. This difference, however, did not achieve statistical significance $(t=1.61, p=.11)$. Further, the high media users felt marginally more creative $(t=1.88$, $p=.06)$, and marginally more engaged $(t=1.72, p=.08)$ than their low media user counterparts during moments of boredom. It is also interesting to note that the high media users reported deriving more meaning from activities during boredom, but this difference was not significant $(t=1.22, p=.22)$. Indeed, the high media users reported slightly higher positive experiential outcomes during boredom and less negative outcomes during anxiety than their low media users counterparts. This finding is telling given the emergence of significant group differences yet lack of significance in the linear and mixed models. 


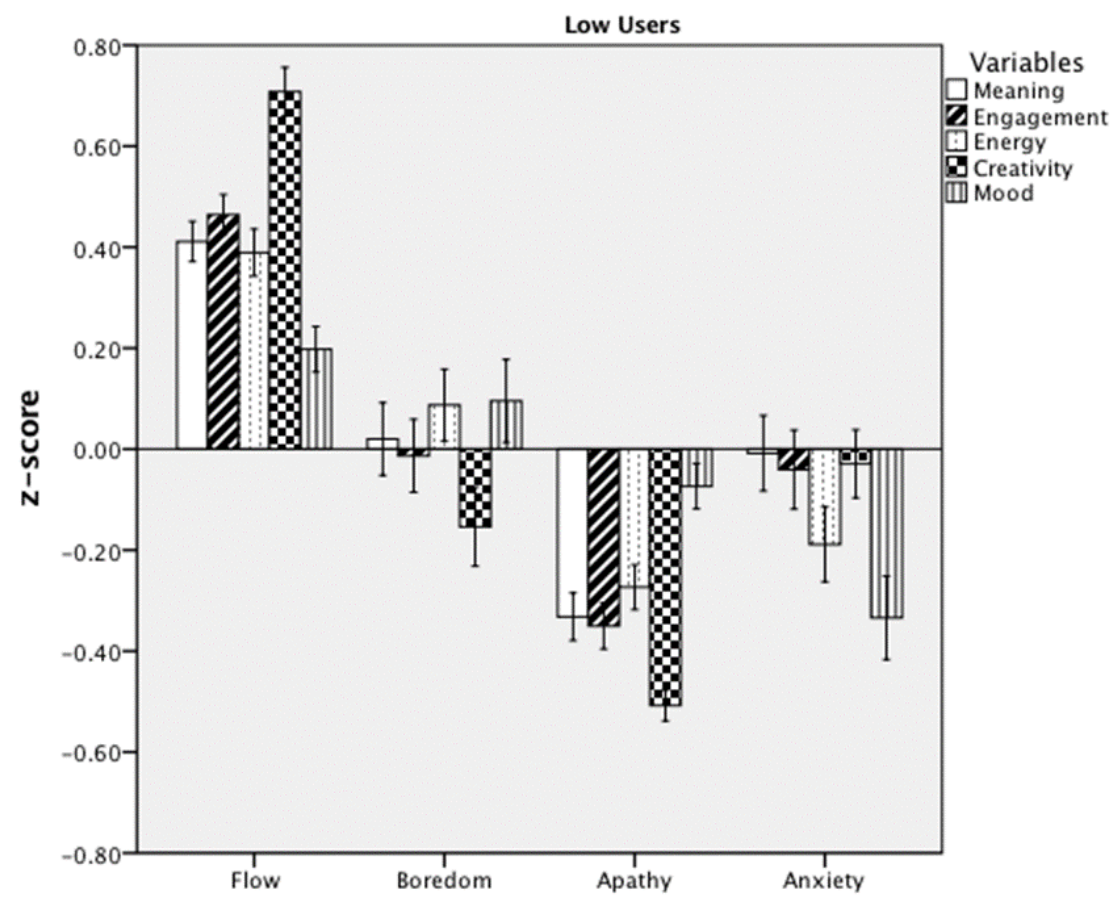

Figure 3. Quality of Experience Across Quadrants: Low Media Users Average quality of experience in flow quadrants for low media users $(N=33$ subjects and 1,195 responses). Error bars indicate $+/-1$ standard error

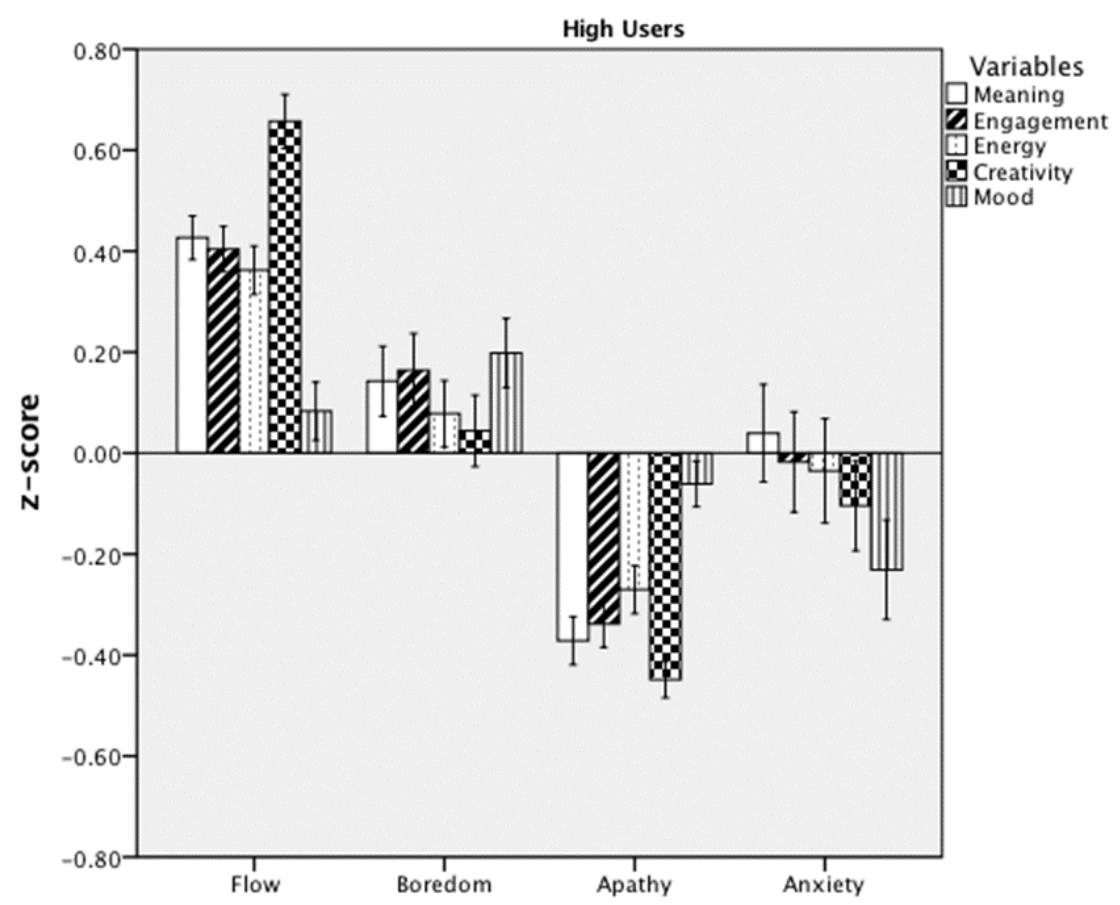

Figure 4. Quality of Experience Across Quadrants: High Media UsersAverage quality of experience in flow quadrants for high media users ( $N=32$ subjects and 1,097 responses). Error bars indicate $+/-1$ standard error 


\section{DISCUSSION}

The findings presented here corroborate previous work by Kross et al. (2013) indicating that frequent media users, on average, report lower moods, which supported hypothesis 1. However, this finding emerged only when dichotomizing media users into low and high groups and was not shown in either the correlational or mixed linear models, which was unexpected. This perhaps suggests that those who used social media more frequently during the week, on average, were more likely to report lower moods in-vivo. It might also suggest that the relationship between media use and mood is non-linear and depends on how, why, or when NDM is used, and if the experience differs for the two groups across specified psychological states. The nuanced approach to identifying differences between low and high media users across flow quadrants indeed helped illuminate patterns of experience that might not have been adequately captured by the linear models.

Because high media users did report being significantly less creative than low media users, hypothesis 2 was supported. This finding echoes Weigel et al. (2008), who suggested that creativity could potentially diminish due to heavy use of multiple NDM platforms that provide students access to a plethora of ideas, which in turn can ramp up competition and uncertainty. It is important to note, however, that Weigel and colleagues focused on adolescents, while our sample consisted of working adults and full-time college students. In addition, because high media users did not report being significantly less engaged than low media users, but did report significantly lower levels of meaning, hypothesis 3 was only partially supported.

Given that high media users reported significantly lower energy levels than their low media user counterparts during the study period, hypothesis 4 was also supported, which to an extent substantiates the theorized process of displacement (Neuman, 1995). That is, heavy use of digitally mediated social networks could displace activities that might otherwise contribute to physical activation. We therefore suggest that individuals limit media use if it interferes with other "activating" behaviours. Because social media is designed to capture attention - and indeed, to be engaging - we argue that heavy media users might therefore not feel subjectively less engaged. Thus, we suggest caution when using NDM as a palliative resource in the absence of finding engagement with offline activities such as work, play, and face-to-face social interaction more broadly.

In the exploratory portion of this study, it was interesting that low and high media users did not differ significantly on their reported satisfaction with each day, but did report being marginally less satisfied with the quality of their week. Given that flow experiences are typically associated with positive emotions, elicit intrinsically motivated behaviours, 
and provide some of the most rewarding human experiences, observed differences in how media users experienced flow, boredom, apathy, and anxiety illuminated differential patterns of behaviour between groups.

Comparing each of the five experiential outcomes (e.g., mood, creativity, engagement, meaning, and energy levels) across the four psychological states outlined by flow quadrants yielded noteworthy results. For example, positive outcomes across all participants, with the exception of mood, were highest in the high-skill/high-challenge (flow) quadrant, and were lowest in the apathy quadrant. Thus, hypothesis 5 was not supported because it was expected that all outcomes would be lowest during apathy and highest during flow. Results showed that mood was in fact higher during boredom than flow, which was unexpected based on previous research (e.g., Nakamura, 1988). The eight flow channels being collapsed into four quadrants here might explain this inconsistency. Specifically, the current measurement might have captured the construct of relaxation (an original component of the 8-channel model) together with boredom. In turn, relaxation typically elicits pleasure rather than enjoyment, especially for individuals that spend most of their day at work (LeFevre, 1988). Participants might therefore rate their moods higher when relaxing. Moreover, research consistently shows that enjoyment is rated higher during activities that engender flow (Delle Fave \& Massimini, 1988; Hektner, Schmidt, \& Csikszentmihalyi, 2007; LeFevre, 1988). This is an important distinction as Csikszentmihalyi notes, (in Hektner, Schmidt, \& Csikszentmihalyi, 2007) "pleasure is conservative; it offers the advantage of conserving energy and making us feel good at a biological level. Enjoyment is...the motivation that keeps us struggling ahead" (p. 283). This contradiction has previously been described as the paradox of work (Hektner, Schmidt, \& Csikszentmihalyi, 2007). As such, people tend to equate relaxation with positive moods more often than work-related activities, perhaps because of social constructions that stigmatize work as the absence of play (Hektner et al., 2007; Schallberger \& Pfister, 2001).

When comparing low and high media users across flow quadrants, noteworthy qualitative trends were observed. It is also important to highlight some marginal differences in how low and high media users experienced boredom. Specifically, high media users reported being marginally more creative and more engaged than low media users when they were bored. Although directionality cannot be inferred (does media use cause boredom or vice versa?), it is possible that heavy media users gravitate towards NDM when they find themselves disengaged or bored. Thus, high media users might be using online social media as a palliative resource, and therefore do not perceive themselves to be less engaged, while low media users refrain from this modality of interaction and are left to find challenge by other means. Further, given that part of digital literacy entails creative 
leveraging of platform-specific affordances - a savvy 'knowhow' - it is also possible that those who use social media more frequently find themselves creatively navigating the online social landscape, thereby feeling more engaged. This is understandable given the positive association between creativity and mood as well as engagement and mood. In turn, the difference of self-reported mood being higher during boredom for high media users might also reflect an association between creative leveraging and positive emotional boosts. Thus, it appears that gravitating towards social media during instances of boredom might indeed provide an emotional buffer for those that use NDM more frequently, as shown by a comparison of means between groups and qualitative examination of experiences in flow quadrants. However, it is unclear whether participants find opportunities for creativity and engagement online, or, if they have become adapted (or addicted), and thus utilize it as a venue for generating positive experiences when such experiences cannot be cultivated offline.

\section{CONCLUSION}

The present study explored the impact of new digital media (NDM) on the quality of everyday experience. Given the substantial increase in accessibility to NDM, and the proliferation of technology for human interaction, it is important to better understand the psychological effects of these platforms. Scholarship on digital media use across the lifespan, and in particular, the increase of social networking among youth, is slowly coming to the fore of multiple fields. Thus, the present study contributes to a rapidly evolving domain of research. Positive psychology can add to this growing body of work by investigating optimal experiences such as flow, creativity, meaning, and engagement along with positive emotional states as they fluctuate in response to an increasingly tech-literate demographic. Our finding that high media users report lower moods, report being less creative, derive less meaning, and report being less energetic than low media users has implications for societies' increased dependence on NDM for work and leisure.

Further, heavy social media use might displace important developmental processes such as face-to-face social interaction and creative pursuits associated with offline social exploration. We have shown here that high and low media users differ in how they experience activities during moments of flow, boredom, apathy, and anxiety. While it is interesting that high media users reported higher moods during boredom than flow, an in-depth analysis of these outcomes revealed that high media users might leverage their knowledge of NDM to boost mood during boredom. However, it will be important in the future to assess the linearity and directionality of these relationships, and to also consider how, and when, social media is used. 


\section{Limitations and Future Directions}

Some limitations and future directions are worth noting. First, the present study did not account for potential moderators. For example, we did not account for demographic variables such as education level or ethnicity in these analyses. However, it is important to note that the low and high media users did not differ significantly with respect to age, gender, or race. Previous studies have shown that moderate versus heavy media usage has differential effects based on demographic variables including socioeconomic status (Hofferth, 2010), and we encourage future studies to take this into greater consideration. Furthermore, this study arguably took a person-centered approach to analyzing data between low and high media users across a broad array of contexts. We therefore neglected to account for situational variables such as the time of day, the ultimate goal of NDM use, or other domain-specific variables such as percentage of time spent at work versus leisure, or alone or with others. In addition, it will be important for future studies to disentangle diverse digital media platforms such as those used explicitly for social networking or passive browsing - and devices such as cell phones, computers, and so forth - and to better understand how different age groups leverage the affordances of NDM to amplify their voices and mobilize others to action.

It will also be crucial to consider how text-based platforms such as email, instant messaging, and "Tweeting" compare with visual media formats such as Instagram, Facebook, Snapchat, and YouTube. Do video-based platforms elicit different responses due to social cues in facial expression, images, colors, or vocal intonation? How might multitasking across platforms impact attention, flow, creativity, and engagement? Myriad NDM platforms are becoming available to individuals of all ages (Twenge, 2013; Weigel, Straughn, Gardner, \& James, 2008). Whether some bring people closer together and foster true connections while others a false sense of connectedness remains to be seen.

Additionally, the use of single item measures for constructs such as mood, creativity, meaning, and engagement might better be captured with multi-item measures that were beyond the scope of the present study. Finally, although we were able to detect differences in means between groups and across experiential situations (broadly), due to the current methodological design, we were unable to infer causality. Future investigations should seek to employ longitudinal and experimental designs in conjunction with cross-sectional studies to shed light on developmental patterns of human experience visà-vis social media use. While the strengths of the present study are manifold, addressing the aforementioned limitations will help scholars contribute to this growing body of work. 


\section{REFERENCES}

Csikszentmihalyi, M. (1988). The flow experience and its significance for human psychology. In M. Csikszentmihalyi \& I. S. Csikszentmihalyi (Eds.), Optimal experience: Psychological studies of flow in consciousness (pp. 15-35). New York, NY US: Cambridge University Press.

Csikszentmihalyi, M. (1990). Flow: The psychology of optimal experience. New York: HarperCollins.

Csikszentmihalyi, M. (1997). Finding flow: The psychology of engagement with everyday life. New York: Basic Books.

Csikszentmihalyi, M., \& Csikszentmihalyi, I. S. (1988). Optimal experience: Psychological studies of flow in consciousness. New York, NY, US: Cambridge University Press.

Csikszentmihalyi, M., \& Larson, R. (1987). Validity and reliability of the experiencesampling method. Journal of Nervous and Mental Disease, 175, 526-536. doi:10.1097/00005053-198709000-00004

Delle Fave, A. D., \& Massimini, F. (1988). Modernization and the changing contexts of flow in work and leisure. In M. Csikszentmihalyi \& I. S. Csikszentmihalyi (Eds.), Optimal experience: Psychological studies of flow in consciousness (pp. 193-213). New York: Cambridge University Press.

Gerbner, G., Gross, L., Morgan, M., Signorielli, N., \& Shanahan, J. (2002). Growing up with television: Cultivation processes. In J. Bryant \& D. Zillmann (Eds.), Media effects: Advances in theory and research (2nd ed.) (pp. 43-67). Mahwah, NJ, US: Lawrence Erlbaum Associates Publishers.

Gupta, R., \& Kabadayi, S. (2010). The relationship between trusting beliefs and web site loyalty: The moderating role of consumer motives and flow. Psychology \& Marketing, 27, 166-185. doi:10.1002/mar.20325

Hayes, A. F. (2006). A Primer on Multilevel Modeling. Human Communication Research, 32, 385-410. doi:10.1111/j.1468-2958.2006.00281.x

Hektner, J. M., Schmidt, J. A., \& Csikszentmihalyi, M. (2007). Experience sampling method: Measuring the quality of everyday life. Thousand Oaks, CA, US: Sage Publications, Inc.

Hofferth, S. L. (2010). Home media and children's achievement and behavior. Child Development, 81, 1598-1619. doi:10.1111/j.1467-8624.2010.01494.x

Hsu, C., Chang, K., \& Chen, M. (2012). Flow experience and internet shopping behavior: Investigating the moderating effect of consumer characteristics. Systems Research and Behavioral Science, 29, 317-332. doi:10.1002/sres.1101 
Hur, J. L., \& Gupta, M. (2013). Growing up in the web of social networking: Adolescent development and social media. Adolescent Psychiatry, 3, 233-244.

Immordino-Yang, M. H., Christodoulou, J. A., \& Singh, V. (2012). Rest is not idleness: Implications of the brain's default mode for human development and education. Perspectives on Psychological Science, 7, 352-364. doi:10.1177/1745691612447308

James, C., Gruner, D. T., Lee, A., \& Mullen, M. (2016). Getting into the fray: Civic youth, online dialogue, and implications for digital literacy education. In H. Jenkins \& S. Shresthova (Eds.), Journal of Digital and Media Literacy, Vol. 4.

Kross, E., Verduyn, P., Demiralp, E., Park, J., Lee, D. S., Lin, N., \& ... Ybarra, O. (2013). Facebook use predicts declines in subjective well-being in young adults. Plos ONE, 8. Larson, R., \& Csikszentmihalyi, M. (1983). The Experience Sampling Method. New Directions For Methodology of Social \& Behavioral Science, 1,541-56.

LeFevre, J. (1988). Flow and the quality of experience during work and leisure. In M.

Csikszentmihalyi \& I. S. Csikszentmihalyi (Eds.), Optimal experience: Psychological studies of flow in consciousness (pp. 307-318). New York, NY, US: Cambridge University Press.

Nakamura, J. (1988). Optimal experience and the uses of talent. In M. Csikszentmihalyi \& I. S. Csikszentmihalyi (Eds.), Optimal experience: Psychological studies of flow in consciousness (pp. 319-326). New York, NY, US: Cambridge University Press.

Nakamura, J., \& Csikszentmihalyi, M. (2009). Flow theory and research. In S. J. Lopez \& C. R. Snyder (Eds.), Oxford handbook of positive psychology (2nd ed.) (pp. 195206). New York, NY US: Oxford University Press.

Neuman, S. B. (1991). Literacy in the television age: The myth of the TV effect. Westport, CT, US: Ablex Publishing.

Piaget, J. (1971). Biology and knowledge: An essay on the relations between organic regulations and cognitive processes. Oxford, England: U. Chicago Press.

Piaget, J., \& Inhelder, B. (1963). Les opérations intellectuelles et leur développment. Intellectual operations and their development. Traité De Psychologie Expérimentale, 7111-155.

Richert, R. A., Robb, M. B., \& Smith, E. I. (2011). Media as social partners: The social nature of young children's learning from screen media. Child Development, 82, 82-95. doi:10.1111/j.1467-8624.2010.01542.x

Rocheleau, B. (1995). Computer use by school-age children: Trends, patterns, and predictors. Journal of Educational Computing Research, 12, 1-17. doi:10.2190/MHUR4FC9-B187-T8H4 
Schallberger, U., \& Pfister, R. (2001). Flow-Erleben in Arbeit und Freizeit: Eine Untersuchung zum 'Paradox der Arbeit' mit der Experience Sampling Method (ESM). Flow experiences in work and leisure: An experience sampling study about the paradox of work. Zeitschrift Für Arbeits- Und Organisationspsychologie, 45, 176-187. doi:10.1026//0932-4089.45.4.176

Schüler, J., \& Nakamura, J. (2013). Does flow experience lead to risk? How and for whom. Applied Psychology: Health and Well-Being, 5, 311-331. doi:10.1111/ aphw.12012 Subrahmanyam, K., Greenfield, P., Kraut, R., \& Gross, E. (2001). The impact of computer use on children's and adolescents' development. Journal of Applied Developmental Psychology, 22, 7-30. doi:10.1016/S0193-3973(00)00063-0

Thatcher, A., Wretschko, G., \& Fridjhon, P. (2008). Online flow experiences, problematic internet use and internet procrastination. Computers in Human Behavior, 24, 2236-2254. doi:10.1016/j.chb.2007.10.008

Twenge, J. M. (2013). Teaching Generation Me. Teaching of Psychology, 40, 66-69. doi:10.1177/0098628312465870

Ulrich, M., Keller, J., Hoenig, K., Waller, C., \& Grön, G. (2014). Neural correlates of experimentally induced flow experiences. Neuroimage, 86, 194-202. doi:10.1016/ j.neuroimage.2013.08.019

Voiskounsky, A. E. (2012). Flow experience in Internet-mediated environments. In D. A. Leontiev (Ed.), Motivation, consciousness and self-regulation (pp. 243-269). Hauppauge, NY, US: Nova Science Publishers.

Vygotsky L.S. (1978). Mind in society. Cambridge, MA: Harvard University Press.

Weigel, M., Straughn, C., Gardner, H., \& James, C. (2008). Multiple worlds: Adolescents, new digital media, and shifts in habits of mind. GoodWork Project Series, Number 53. Retrieved November 30, 2014, from Harvard University, Project Zero Website.

Corresponding author at: Daniel T. Gruner, Department of Psychology, Claremont Graduate University, Claremont, CA, 91711.

E-mail: daniel.gruner@cgu.edu 